EESTI NSV TEADUSTE AKADEEMIA TOIMETISED 1952. I k. nr. 4

\title{
ARHEOLOOGILISED KAEVAMISED TALLINNAS
}

\author{
S. A. TARAKANOVA, \\ ajalooteaduste kandidaat
}

1952. aasta septembris-oktoobris teostati Tallinna Toompeal arheoloogilisi kaevamisi, mis olid esimesteks linna ajaloos.

Tööd teostati Toomkiriku juures Toomkooli tän. nr. 21 hoovis, kus avati $36 \mathrm{~m}^{2}$ suurune kaevand, ja Eesti NSV Tervishoiuministeeriumi esisel platsil, kus avati kaks kaevandit, suuruselt $12 \mathrm{~m}^{2}$ (nr. 1) ja $32 \mathrm{~m}^{2}$ (nr. 2).

Kaevamistele eelnes suur ettevalmistustöö seoses arhiivmaterjalide kogumisega Toompea topograafia kohta. Tihedalt täisehitatud Toompeal oli kaevamiste koha valik raskendatud. Siiski õnnestus ära märkida mōningad punktid, kus oli soovitav ja võimalik kaevamisi teostada. Arvestades, et 1952. aasta tööd olid selgitusliku iseloomuga, teostati kaevamisi ainult kahes ülalmärgitud kohas.

1952. aastal alustatud kaevamiste eesmärgiks on selgitada rida Tallinna ajaloosse puutuvaid küsimusi, mida kirjalikes allikais on väga vähe või üldse mitte valgustatud. Oks neid küsimusi on muinaseesti asula tekkimise aeg Tallinna kohale ja linna enda tekkimise aeg. On teada, et Lääne-Euroopa kodanlikud ajaloolased kuhjasid selle küsimuse ümber rea ebaõigeid ja ka lausa võltse väiteid, püüdes tõestada, et Tallinna asutasid tulnukad Lääne-Euroopast (taanlased 1219. aastal).

Tallinna vanimat ajalugu valgustavate kirjalike allikate puudulikkus andis kodanlikele ajaloolastele vabad käed mitmesugusteks väljamõeldisteks. Seejuures ignoreerisid kodanlikud ajaloolased araabia geograafi Idrisi teadet 1154. aastast selle kohta, et eestlaste linn Kolõvan (Tallinn) eksisteeris juba XII sajandil, ja Läti Hendriku kroonika andmeid, mis mainivad eesti linnuse olemasolu Tallinna kohal juba enne taanlaste tulekut. Küsimuse oleks aidanud lahendada arheoloogilised kaevamised Tallinnas, kuid kodanliku diktatuuri ajal neid Eestis ei teostatud.

1952. aasta kaevamised Tallinnas algasid Tallinna Linna TSN Täitevkomitee initsiatiivil ja toimusid Eesti NSV Teaduste Akadeemia Ajaloo Instituudi osavõtul.

Kaevamiste teiseks eesmärgiks oli arheoloogilise materjali põhjal selgitada eesti linna kultuuri iseloomu ja arengut, sest eesti linnana esineb Tallinn tema tekkimisest alates kuni meie päevini. Tallinna muinsuste uurimisega tegelesid ka kodanlikud ajaloolased, arheoloogid ja kunstiteadlased, kuid kogu nende tähelepanu oli suunatud võõramaise kultuuri sugemetele. Kohalikku, eesti kultuuri ei uuritud küllaldaselt ning puudusid tõsised püüded uue materjali saamiseks kaevamiste teel.

Kolmandaks ülesandeks oli arheoloogilise materjali alusē jälgida eesti ja vene rahva kultuurisidemeid. On teada, et Novgorod ja Pskov 
pidasid XI-XII sajandist alates Balti mere kaudu laialdast kaubavahetust paljude Lääne-Euroopa linnadega. Sellel kaubateel seisis Tallinn. Tallinna ja Vana-Viene linnade vahel olid majanduslikud ja kultuurilised sidemed vältimatud. Seda näitab selliste nimetuste esinemine vanas Tallinnas nagu «Vene ots» ja «Vene tänav», mis viis Toompealt mereni.

Tähendatud ülesannet ei saa muidugi lahendada ühe-kahe aasta jooksul teostatud kaevamistel saadud materjali alusel, seda enam aga mitte 1952. aastal väga väikesel pindalal teostatud esimeste, ainult selgitusliku iseloomuga kaevamiste materjali alusel. Selleks on vaja kaevamisi teostada mitmes kohas, nii Toompeal kui ka all-linnas.

1952. aasta kaevamiste peasihiks oli Tallinna Toompea kultuurkihtide iseloomu väljaselgitamine. Sellelaadilist tööd tegemata ei saa Tallinnas teostada edasisi teaduslikult põhjendatud kaevamisi.

Tehes esialgseid kokkuvõtteid 1952. aasta uurimistest (lõplikke järeldusi võib teha alles pärast kaevamistel saadud materjali pōhjalikku läbitöötamist), võib öelda järgmist.

1. Tervishoiuministeeriumi hoone esisel platsil teostatud kaevamised andsid uut topograafilist materjali vana Toompea kohta. Selgus, et selles osas oli Toompea mäel väga järsk langus. Järelikuit, olles teistest, peaaegu püstloodsete veergudega külgedest ligipääsmatu, oli Toompea raskesti ligipääsetav ka sellest küljest, kujutades endast vanasti looduslikku kindlust. See Toompea kõrgendiku iseärasus võis olla põhjuseks, et linn hakkas väga varakult kasvama ka tema jalamil.

Hiljem piirati see osa kõrgendiku jalamist kivimüüriga, mille jäänused on märgitud mõningatel XVII sajandi plaanidel. Kaevamistel paljastati osa sellest müürist, mille kõrgus on kuus meetrit. Kui arvestada, et vanalinna müüre hakati ehitama XIII sajandi keskel, võib arvata, et avastatud müür ei ole hiljem ehitatud. Tema ehitamise täpsema aja saab määrata, uurides müürialust kultuurkihti, mis ongi üheks edasiste kaevamiste sihiks.

2. Kaevamised Toomkooli tänavas andsid selge ettekujutuse Toompea selle osa kultuurkihtide stratigraafiast. Kultuurkihi paksus oli siin 5,5 meetrit. Neid kihte läks korda teatud määral knonoloogiliselt jaotada, mida suurel määral soodustasid müntide leiud. Võib märkida järgmisi kihte: esimene, paksusega kuni $40 \mathrm{~cm}$, - XX sajand; teine, paksusega kuni 1 meeter, - XIX sajand; kolmas - 1,5-2 meetrit - XVIII sajand ja neljas - 2-2,5 meetrit - XVII-XVI sajand. Sellest vanemat kihti kaevamistel ei avastatud. Kultuurkiht, mis asus puutumatul pinnasel, koosnes savist ja suurest hulgast mitmesuguse suurusega paekividest, millele lisandus sütt ja peenestatud tellistega segatud krohvitükke. Sellest kihist leiti loomakonte, mitmesuguseid raudesemeid ja glasuuriga kaetud punasest savist keraamikat.

Puutumatu pinnase uurimine kaevandite maa-alal ja samuti geoloogiliste puurimiste andmed Toompea sellest osast viivad järeldusele, et siin asus veel kuni XVI sajandini paemurd, mistõttu vanemad kultuurkihid on hävinenud.

3. Kaevamised Toomkooli tänavas andsid huvitavat materjali, mis kuulub XVI-XVIII sajandisse, eriti keraamikat. Sisseveetud savi-, fajanss- ja portselannõude tükkide hulgas leiti punasest savist kohaliku päritoluga mitmevärviliste ja mitmesuguse ornamendiga glasuuritud nõude kilde. Seda materjali, mis praegustel kaevamistel esmakordselt avastati, võib kasutada Tallinna linna käsitöö ja eesti rahvakunsti uurimiseks.

Erinevalt sisseveetud fajanss- ja portselannõudest, mida tarvitasid 
privilegeeritud ühiskonnakihid, kuulusid punasest savist glasuuritud nõud lihtrahvale - tavalisele linlasele.

XVI-XVII sajandi kihtidest leiti ka rohelise vaabaga ahjukahleid ja savinõusid. Rohelise vaabaga kahleid ja nõusid tarvitati sel ajal Pskovis, klis teisevärvilist vaapa peaaegu üldse ei esinenud. Tallinnas, Toompea kaevamistel on taolise keraamika leiud küllaltki haruldased. Nad osutavad kultuurisidemete olemasolule tol ajal Tallinna ja Pskovi vahel.

4. Tervishoiuministeeriumi hoone esise kaevandi nr. 2 alumistest horisontidest ja Toomkooli tänava kaevandi XVI-XVII sajandi kultuurkihist leiti materjali, mis oli siia sattunud juhuslikult, kuid kahtlemata Toompea enda territooriumilt. See materjal räägib sellest, et as u 1 a oli si in olemas juba ammu en ne XIII sajandit. Niisuguste leidude hulka kuulub pronksist käevöru, mis on punutud kolmest traadist ning mis kuulub XII sajandisse, segmendikujuline kivist värtna keder samast sajandist ja teisi esemeid.

Peale selle leiti kaevamistel materjali, mis lubab oletada, et eestlaste asula Toompea kõrgendikul tekkis juba X sajandil. Leiti keraamikat, mis on küll valmistatud käsikettal, kuid mille juures esineb ka palju primitiivse tehnika jooni. Need nõud on valmistatud urbsest segust, jämeda liiva tunduva lisandusega, nõrgalt põletatud, koreda, tumedavärvilise pealispinnaga ja joonornamendiga nõude ülemistel osadel, mille väljatöötus on mõnikord kohmakas. Nõude kuju on analoogiline nende nõudega, mis on leitud põhjapoolsete linnade Vana-Vene (Pskovi ja Vana Laadoga) IX -X sajandi kihtidest. Sama tüüpi nõusid on leitud ka Gnezdovo kääbastikust Smolenski lähedalt, mis kuulub IX $-X$ sajandisse.

Väga huvitav on Tallinna Toompealt kaevamistel leitud tundmatu otstarbega saviketta fragment, mis on valmistatud samas algelises tehnikas. Selle ketta üks pool on ilustatud kohmakalt väljatöötatud sämpudega, mis on paigutatud kontsentriliste ringidena.

Leitud väikesed, väga varasest ajast pärinevad raudnoad viitavad samuti võimalusele avastada Tallinna Toompeal muistset kultuurkihti, mille vanus ulatub X sajandisse. See võimalus põhineb veel sellel, et muistne asula ei hõivanud mitte kogu Toompea kõrgendikku, vaid ainult osa sellest, ja vanu kultuurkihte võib avastada Toompea muudes osades. Näitena võib tuua Pskovi kremli maanina järkjärgulist asustamist meie ajaarvamise esimesel aastatuhandel, mida läks korda avastada arheoloogiliste kaevamistega Pskovis 1946-1949. aastal.

Väikese kivitalva katkendi leidmine osutab kuskil Tallinna territooriumil asunud neoliitilise asula olemasolule.

1952. aasta kaevamised olid esimeseks sammuks vana Tallinna arheoloogilisel uurimisel. Ulalnimetatud ülesannete lahendamiseks tuleb jätkata kaevamisi Toompeal ja samaaegselt alustada kaevamisi all-linnas. 
EESTI NSV TEADUSTE AKADEEMIA TOIMETISED 1952. I k. nr. 4 ИЗВЕСТИЯ АКАДЕМИИ НАУК ЭСТОНСКОИ ССР 1952. ТоМ I, № 4

\title{
АРХЕОЛОГИЧЕСКИЕ РАСКОПКИ В ТАЛЛИНЕ
}

\author{
C. А. ТАРАКАНОВА, \\ кандидат исторических наук
}

В сентябре-октябре 1952 года были проведены археологические раскопки на таллинском Вышгороде (Тоомпеа), первые раскопки в истории города.

Работы производились во дворе домов по улице Тоомкооли, 21, близ Домской церкви, где был заложен раскоп в 36 кв. метров, и на площадке у главного подъезда здания Министерства здравоохранения ЭССР. Здесь имелись два раскопа: № 1 в 12 кв. метров и № 2 в 32 кв. метра.

Раскопкам предшествовала большая подготовительная работа, связанная со сбором архивных сведений по топографии Вышгорода. Большая плотность его застройки значительно затрудняла выбор места для раскопок. Все же удалось наметить несколько пунктов, где было бы желательно и возможно провести раскопки. Имея в виду, что работы 1952 года носили разведывательный характер, раскопки производились только в двух вышеуказанных местах.

Раскопки, начатые в 1952 году, преследуют цель собирания материала для выяснения ряда вопросов истории древнего Таллина, очень слабо освещенных или совсем не освещенных письменными источниками. Одним из них является вопрос о времени возникновения древнего эстонского поселения на месте Таллина и времени возникновения самого города. Известно, что буржуазные западноевропейские историки нагромоздили вокруг этого вопроса целый ряд неверных и лживых утверждений, доказывая, что Таллин основали западноевропейские пришельцы (датчане в 1219 году).

Недостаточность письменных источников по древнейшей истории Таллина создавала простор для различных измышлений буржуазных историков. Свидетельство арабского географа Идриси от 1154 года о том, что эстонский город Колывань (Таллин) существовал уже в XII веке, и данные Хроники Генриха Латвийского, упоминающего об эстонском городище в Таллине еще до прихода дапчан, буржуазные историки игнорировали. В разрешении этого вопроса могли бы помочь раскопки Таллина, но при буржуазной диктатуре в Эстонии они ни разу не производились.

В 1952 году раскопки в Таллине начались по инициативе Таллинского гсрсдского совета и проходили при участии Института истории АН ЭССР

Другой вопрос, который встал перед экспедицией, - это выяснение на археологическом материале характера и развития культуры эстонского города, каковым и является Таллин с момента его возникновения до наших дней. Изучением древностей Таллина занимались и буржуазные историки, археологи и искусствоведы, но все их внимание было направ- 
лено на изучение элементов иноземной, привнесенной сюда культуры. Культура местная, эстонская не изучалась в достаточной мере, серьезного стремления получить новые материалы путем раскопок не было.

Третьим вопросом, вставшим перед экспедицией, является прослеживание на археологическом материале культурных связей между эстонским и русским народами. Известно, что Великий Новгород и Псков начиная с XI-XII веков вели через Балтийское море обширную торговлю с многими городами Западной Европы. На этом торговом пути стоял Таллин. Неизбежно устанавливались экономические и культурные связи Таллина с древнерусскими городами. Об этом свидетельствует наличие в древнем Таллине «Русского конца» и «Русской улицы», проходившей от таллинского Вышгорода к морю.

Разумеется, что разрешение намеченных задач не может быть осуществлено на материале раскопок одного-двух лет, а тем более на материале первых раскопок 1952 года, очень небольших по своей площади, имеющих разведывательный характер. Для этого потребуется проведение раскопок в нескольких местах, как на Вышгороде, так и в Нижнем городе.

Основная цель раскопок 1952 года состояла в том, чтобы изучить характер культурных напластований таллинского Вышгорода. Без проведения такого рода рабсты нельзя с достаточной научной обоснованностью производить дальнейшие раскопки Таллина.

Подводя предварительные итоги проведенных исследований 1952 года (окончательные выводы можно сделать только после изучения полученного из раскопок материала), можно сказать следующее.

1. Раскопки у здания Министерства здравоохранения дали новый материал по топографии древнего Вышгорода. Выяснилось, что в этой части Вышгородский холм имел очень крутой спуск. Следовательно, являясь с других сторон, где имелись почти отвесные склоны, недоступным, Вышгородский холм был трудно доступным и в этой своей части, представляя собою в древности естественную крепость. Эта же особенность Вышгородского холма могла явиться причиной того, что город очень рано начал расти и у его подножия.

В дальнейшем подножие этой части холма было обнесено крепостной каменной стеной, остатки которой обозначены на некоторых планах XVII века. Раскопками вскрыта часть этой стены, высотою в шесть метров. Если учесть, что стены старого города начали строиться в середине XIII века, можно думать, что вскрытая стена построена не позже этого времени. Более точное время ее постройки можно будет установить при изучении характера культурного слоя под ее основанием, что явится одной из задач будущих раскопок.

2. Раскопки по улице Тоомкооли дали отчетливое представление о стратиграфии культурных слоев в этой части Вышгорода, мощность которых здесь составляла 5,5 метра. Удалось в известной мере расчленить эти слои хронологически, чему в значительной степени помогли находки монет. Намечаются следующие слои: первый, мощностью до 40 см, $\mathrm{XX}$ век; второй, мощностью приблизительно до одного метра, - XIX век; третий - до 1,5-2 метров - XVIII век и четвертый - в 2-2,5 метра XVII-XVI века.

Более древнего слоя в раскопках не обнаружено. Культурный слой, лежащий на материковой скале, состоял из глины, большого количества плитняковых камней различной величины со включением углей и кусков известкового раствора с примесью мелко толченого кирпича. В этом слое найдены кости животных, различные железные предметы и керамика красной глины с поливой. 
Изучение материковой поверхности на территории раскопок, а также данные геологического бурения в этой части Вышгорода приводят к заключению, что еще до XVI века здесь происходила ломка плитнякового камня, во время которой и были уничтожены более древние культурные слои.

3. Раскопки по улице Тоомкооли дали интересный материал XVI-XVIII веков, особенно керамический. Среди обломков привозной глиняной, фаянсовой и фарфоровой посуды найдены фрагменты посуды из красной глины местного производства с поливой разного цвета и разнообразного орнамента. Әтот материал, впервые ставший известным благодаря нынешним раскопкам, может быть использован для изучения таллинского городского ремесла и эстонского народного искусства.

В отличие от привозной фаянсовой и фарфоровой посуды, употреблявшейся привилегированными слоями общества, поливная посуда из красной глины являлась принадлежностью простого народа - рядовых горожан.

В слоях XVI-XVII веков найдены также печные кафели и глиняная посуда с зеленой поливой. Зеленая полива кафелей и посуды употреблялась в это время в Пскове, где иные цвета поливы почти совсем не встречаются. Находки этого типа керамики при раскопках таллинского Вышгорода довольно редки. Они указывают на наличие культурных связей Таллина и Пскова того времени.

4. В нижних горизонтах культурного слоя на раскопе № 2 у здания Министерства здравоохранения и в культурном слое XVI-XVII веков на раскопе по улице Тоомкооли найден материал, попавший сюда случай̀н, но, несомненно, с территории самсго Вышгорода. Этот материал говорит о том, что поселение 3 десь существовало еще $з$ адолго до XIII в ека. К таким находкам относится бронзовый браслет, витый из трех проволок, датируемый XII веком, каменное пряслице сегментовидной формы того же времени и другие вещи.

Более того, в раскопках найден материал, который дает возможность предполагать, что эстонское поселение на Вышгородском холме возникло уже в X веке. Найдена керамика, хотя и изготовленная на ручном круге, но имеющая многие черты примитивной техники. Такая посуда имеет пористое тесто со значительной примесью крупного песка, слабый обжиг, шероховатую поверхность темного цвета и линейный орнамент в верхней части сосудов, выполненный иногда небрежно. Форма сосудов аналогична той посуде, которая найдена в слоях IX-X веков северных древнерусских городов (Пскова и Старой Ладоги). Такого же типа посуда известна и в Гнездовском могильнике, близ Смоленска, датируемого IX $-\mathrm{X}$ веками.

Особенно интересен найденный при раскопках таллинского Вышгорода фрагмент глиняного диска неизвестного назначения, изготовленного той же примитивной техникой. Одна сторона этого диска украшена поперечной небрежно выполненной насечкой, расположенной концентрическими кругами.

Найденные маленькие железные ножи весьма ранней формы также указывают на возможность открытия на таллинском Вышгороде древнего культурного слоя не моложе X века. Эта возможность основывается еще и на том, что древнее поселение могло занимать не всю территорию Вышгородского холма, а только часть его, и древние культурные слои могут быть открыты в других частях таллинского Вышгорода. В качестве примера можно указать постепенное заселение в первом тысячелетии нашей эры Псковского кремлевского мыса, что удалось обнаружить археологическими раскопками Пскова в 1946--1949 годах. 
Находка обломка маленького каменного тесла указывает на наличие где-то на территории Таллина поселения эпохи неолита.

Раскопки 1952 года явились первым шагом в археологическом изучении древнего Таллина. В целях разрешения вышеуказанных проблем следует продолжить раскопки на Вышгороде и одновременно начать раскопки в Нижнем городе.

Институт истории материальной культуры Академии Наук СССР 